\title{
Factors Affecting the Establishment of Teledermatology in Iran; A Mixed-Method Study
}

\author{
Sakine Beygom Kazemi ${ }^{1}$, Mehrnoosh Jafari ${ }^{*}$, Seyed Mojtaba Hosseini ${ }^{1}$, Ali Maher ${ }^{2}$, \\ Mohammadkarim Bahadori ${ }^{3}$
}

1. Department of Health Services Management, Islamic Azad University, Tehran North Branch, Tehran, Iran.

2. School of Management and Medical Education Management, Economics and Health Policy, Shahid Beheshti

University of Medical Sciences: Tehran, Iran

3. Health Management Research Center, Baqiyatallah University of Medical Sciences, Tehran, Iran

\section{Article Type:}

Original Article

\section{Article History:}

Received: 10 Jan 2020

Revised: 15 Feb 2020

Accepted: 29 Feb 2020

\section{*Correspondence:}

Mehrnoosh Jafari, Associate Professor, Department of Health Services Management, North Tehran Branch, Islamic Azad University, Tehran, Iran

$$
\text { mehr_j134@yahoo.com }
$$

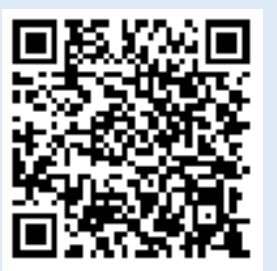

DOI: 10.29252/jorjanibiomedj.8.1.11

\begin{abstract}
Background and objective: One of the important and common applications of telemedicine is the diagnosis and treatment of skin diseases. However, teledermatology requires further commitments to provide standard services and appropriate electronic data transfer for reliable diagnostics to comply with technical standards and legal requirements. The present study aimed to determine the factors affecting the establishment of Teledermatology in the qualitative and quantitative sections.
\end{abstract}

Methods: A mixed-method study (including quantitative and qualitative sections) was conducted in 2018. In the qualitative section, experts were selected by purposive sampling and the data were collected through 2 focus group discussions and 6 semi-structured interviews. The content of sessions and interviews were transcribed and then analyzed by the content analysis method. In the quantitative section, 384 participants were selected randomly. The data were collected using a researcher-made questionnaire whose validity and reliability were confirmed. Data analyses were performed in SPSS.

Results: A total of 8 categories and 58 subcategories were extracted. The 8 categories of the factors affecting the establishment of teledermatology in Iran included service provider, service recipient, structural, technological, economic, policymaking, legal, and cultural. Cultural factors $(3.95 \pm 0.77)$ and policymaking factors (3.22 \pm 0.84$)$, respectively, had the highest and the lowest effects on the establishment of teledermatology in Iran.

Conclusion: Factors affecting the establishment of Teledermatology are diverse and extensive, which the most effective factors were cultural factors, technological factors and factors related to service providers. These findings can help the policymakers and managers interested in the establishment of teledermatology in Iran.

Keywords: Telemedicine; Teledermatology; Mixed methods study

Copyright $@$ 2018, Jorjani Biomedicine Journal has published this work as an open access article under the terms of the Creative Commons Attribution License (http://creativecommons.org/licenses/by-nc/4.0/) which permits noncommercial uses of the work while it is properly cited. 


\section{Introduction}

The term "telemedicine" was first introduced to the medical literature in 1920 (1). As defined by the World Health Organization (WHO), telemedicine refers to the provision of health services by all health care professionals using telecommunication technologies to exchange credible information for the diagnosis, treatment and prevention of diseases and injuries, research, evaluation, and continuous training of health care providers when distance is considered a vital factor (2). Increased access to health care services, increased and continuous provision of health care, patient training, timely treatment, increased access to medical information, and continuous development of education are some advantages of telemedicine (3). One of the major and common applications of telemedicine is teledermatology (4). The application of teledermatology to provide specialized skin services can lead to a faster access to specialized medical services regardless of geographical location, reduce the waiting time to receive services, and reduce the costs of specialized services (visitation fee, transportation, and accommodation) (5). Teledermatology can be employed in real time using video conferencing systems (6), a method in which medical images are received and stored by the physician and sent to the specialist (5). Teledermatology can improve access to specialized skin services by overcoming existing barriers (7). With slight changes over time, teledermatology is still defined as the application of telecommunication technologies to provide virtual communication between the applicants for skin healthcare services and dermatologists (8). In teledermatology, clinical information and images of skin lesions can be communicated between a general practitioner and a dermatologist, between dermatologists, or even between a patient and a dermatologist for obtaining diagnostic and therapeutic recommendations (9). It has been shown that teledermatology is an effective tool of triage that can reduce the waiting time for the initial intervention in specialized skin services in patients with skin cancer (10). Numerous studies have been conducted on teledermatology in different countries of the world. The results of a study showed that the establishment of teledermatology reduced the waiting time of patients for skin healthcare services from 84.6 days to 6.7 days. In addition, the number of patients examined through this system increased to 901 per year and 2.63 per hour, on average (11). In a study in Botswana, the results indicated that teledermatology was considered an appropriate option for HIVpositive patients as an alternative to face-toface consultations (12). Moreover, the increased waiting time for skin healthcare services and visitation costs can endanger the patient's health and reduce the quality of therapeutic outcomes (13). Despite the obvious benefits of teledermatology for widespread access to skin healthcare services, this system has not gone through a period of uniform growth and development (14). Most cases of skin diseases are chronic conditions that require a long time for care, treatment, and follow-up. The trips made to visit a dermatologist in a hospital, a specialized clinic or his/her office can be both costly and time-consuming (15). Considering the increasing tendency of various fields of medical sciences to apply this technology in providing healthcare services, the visual nature of such diseases is an ideal area for the introduction and application of telemedicine, as well as an opportunity to change and 
transform the traditional way of communication between physician and patient, especially after the advent of digital photography (16). The ultimate goal of this technology is to increase the effectiveness of healthcare services by increasing the continuity and accuracy of healthcare services and reducing the time required to provide diagnoses. In fact, teledermatology has attracted the attention of patients and healthcare providers and policymakers due to its capability to provide high-quality and less expensive specialized healthcare services. Since, recognizing the factors influencing the establishment of teledermatology can lead to more efficient and effective implementation, present study hence aims to determine these factors to establish teledermatology in Iran. In this regard, a mixed method was applied to provide a stronger interpretation because quantitative and qualitative methods reinforce each other's strengths and remove each other's weaknesses.By combining quantitative and qualitative findings, a general view of the findings can be obtained that is not possible by any of the quantitative or qualitative methods alone. Using both types of data allows researchers to generalize the results of the sample to the Society and gain a deeper understanding of the phenomenon.

\section{Materials and Methods}

A mixed-method study (including quantitative and qualitative sections) was conducted in 2018.

\section{Qualitative study}

The statistical population in this section consisted of provincial and national managers of the Center for Statistics and Technology Management of the Ministry of Health, dermatologists, professors and faculty members in the field of health care management, and faculty members from research centers.

The participants were selected based on purposive sampling method. Accordingly, those who met the preset criteria were identified, and then their views were elicited to identify the experts. The criteria set for the selection of participants were familiarity and mastery over the research subject, having a managerial background in the health system, at least ten years of work experience, employment in public and private medical centers, familiarity with information technology and its importance in the health system and electronic services in the health system, and having a relevant university degree.

The data were collected through 2 sessions of focus group discussion and 6 semi-structured interviews. Main question of interview guide was "In your opinion, what factors are effective in establishing a telematology trap in Iran". The research team prepared and sent invitations to experts to participate in the focus group discussion. The invitation contained information about the title, objectives, time, and place of sessions. Before the beginning of the focus group discussion, the participants were briefed on the research nature, objectives, and procedure. Then 2 sessions of focus group discussion were held for 2.5 and 3 hours. During these sessions, the participants freely expressed their opinions and the meeting coordinator tried to direct the session and maintain its dynamicity. The interviews were also conducted in a quiet place away from any distraction. The participants were interviewed during 35- 55 minutes.The interviewees were also briefed on the research objective. The interviews and focus group discussions were finished whenever data saturation was achieved. Data saturation refers to the point in the research 
process when no new information is discovered in data analysis. The participants were assured that their information will be kept confidential and the content of interviews and focus group discussion will be used for data analysis anonymously. The transcribed content of interviews and focus group discussion were provided to the participants and they were asked to confirm the accuracy of data.

To increase the research acceptance, combinative methods and the observer review technique were employed. Accordingly, sufficient time was allocated to data collection and the subject was considered from different aspects. Moreover, complementary views were collected and the review of manuscripts was provided by colleagues. To increase the data transferability, data collection and analysis were simultaneously performed on appropriate samples. To add to the data consistency, the data were analyzed by various researchers and external observers. To increase verifiability, the whole research process was explained from beginning to end(17-19).

The data obtained from interviews were analyzed using thematic analysis. In this regard, First, all the transcripts were carefully read several times and Important relevant parts were identified. Then, the subgroups were assigned to each category. After making sure that the created categories represent all the data, the themes were extracted and the data was merged(20).

\section{Quantitative study}

In this section, a cross-sectional descriptiveanalytical study was performed. The research population included two groups of experts in information technology and dermatologists in all universities of medical sciences. Due to the lack of accurate statistics information from the target population, the Cochran's formula was used to determine the maximum required sample. Based on the tendency of $50 \%$, the error rate of $5 \%$ and the confidence interval of $95 \%(=0.05, d=0.05, p=0.5 a)$, the sample size was determined 384 people.

$\mathrm{n}=\frac{\mathrm{z}^{\mathrm{z}} \mathrm{pq}}{\mathrm{d}^{\mathrm{z}}}=384$

The sampling method was cluster sampling. Given that the research society has 10 clusters, which corresponds to the ten national poles of the country's medical universities, in order to achieve the best estimates of the target society, first 6 clusters were randomly selected. Therefore, the sample size allocated to each cluster was 64 people. Selection of samples within clusters has been done by convenient sampling.

To develop the research questionnaire, the results of the qualitative section were extracted and then their content validity was investigated by quantitative and quantitative methods. To assess the qualitative validity, the questions were provided to a panel of 10 professionals, including professors of health care management, dermatologists, IT experts, and health policymakers, to make their corrective comments on the grammar, sentence structure, and phrases. The quantitative content validity was assessed by using Content Validity Ratio (CVR) and Content Validity Index (CVI). For CVR, members of the above-mentioned panel were asked to review all questions and categorize them as "necessary", "useful but unnecessary", and "unnecessary". Finally, CVI was calculated by using the following formula:

$\mathrm{CVR}=\frac{\mathrm{n}_{\mathrm{E}}-\frac{\mathrm{N}}{2}}{\frac{\mathbb{N}}{2}}$ 
The reliability of the questionnaire was assessed by using the test-retest method. Based on the opinions of 50 experts, the correlation coefficient in a 10-day interval was reported to be 0.934 .

The research questionnaire consisted of two parts: the demographic information of the participants and the factors affecting the establishment of teledermatology. The questionnaire was scored based on a 5-point Likert scale (1: totally disagree, 2 : disagree, 3 : no common, 4: agree, 5: totally agree). Considering the geographical distribution of the participants, the questionnaires were sent to the participants as a web form. The electronic version of the questionnaire was

sent to those whose email address was available and those who were willing to receive and fill out the questionnaire electronically.
The questionnaire delivery, completion, and return were followed up through three remainders: telephone, email, and SMS. The obtained data were statistically analyzed in SPSS-21.

\section{Results}

\section{Qualitative study}

A total of 8 categories and 58 subcategories were extracted. The 8 categories of the factors affecting the establishment of teledermatology in Iran included service provider, service recipient, structural, technological, economic, policymaking, legal, and cultural (Table 1).

Table 1: The factors affecting the establishment of teledermatology in Iran

\begin{tabular}{|c|c|c|c|c|c|}
\hline \multirow{2}{*}{$\begin{array}{l}\text { Main } \\
\text { categories }\end{array}$} & \multirow[t]{2}{*}{ Sub-categories } & \multicolumn{2}{|c|}{ CVR } & \multirow[t]{2}{*}{ Mean } & \multirow{2}{*}{$\begin{array}{l}\text { Standard } \\
\text { deviation }\end{array}$} \\
\hline & & Score & Result & & \\
\hline \multirow{8}{*}{$\begin{array}{l}\text { Service } \\
\text { provider }\end{array}$} & Interaction between general practitioners and specialists & 0.8 & Confirmed & 3.27 & 1.03 \\
\hline & $\begin{array}{c}\text { Increasing the awareness and knowledge of service } \\
\text { providers }\end{array}$ & 0.8 & Confirmed & 3.20 & 0.96 \\
\hline & $\begin{array}{l}\text { Increasing the individual and professional skills of service } \\
\text { providers }\end{array}$ & 1 & Confirmed & 3.31 & 0.88 \\
\hline & $\begin{array}{l}\text { Unequal geographical distribution and lack of specialists } \\
\text { in remote areas }\end{array}$ & 0.8 & Confirmed & 3.20 & 0.98 \\
\hline & $\begin{array}{l}\text { Stockholders' understanding of the results of using } \\
\text { technology in the service delivery process }\end{array}$ & 0.8 & Confirmed & 3.28 & 0.98 \\
\hline & Determination of an acceptable level of patient safety & 0.8 & Confirmed & 3.23 & 0.04 \\
\hline & Accuracy of diagnosis & 1 & Confirmed & 3.27 & 0.96 \\
\hline & $\begin{array}{l}\text { Patient-physician relationship regarding adherence to the } \\
\text { treatment plan }\end{array}$ & -0.8 & Rejected & & - \\
\hline
\end{tabular}




\begin{tabular}{|c|c|c|c|c|c|}
\hline & Need for distance medical training & 0.8 & Confirmed & 3.30 & 0.97 \\
\hline & Validation of service providers & -0.8 & Rejected & & \\
\hline \multirow{13}{*}{$\begin{array}{l}\text { Service } \\
\text { recipient }\end{array}$} & Burden of visits & 0.8 & Confirmed & 3.59 & 0.93 \\
\hline & Patient satisfaction & 0.8 & Confirmed & 3.63 & 0.93 \\
\hline & Waiting time between preventive care and treatment & 0.8 & Confirmed & 3.49 & 0.98 \\
\hline & Unpredictable behavior of patients in decision-making & -0.8 & Rejected & \multicolumn{2}{|c|}{-} \\
\hline & Accessibility & 0.8 & Confirmed & 3.59 & 0.89 \\
\hline & Interface-free connection between users and the system & 0.8 & Confirmed & 3.54 & 0.95 \\
\hline & Information access through secure encryption & 0.8 & Confirmed & 3.54 & 0.96 \\
\hline & Expansion of high-quality medical services & 0.8 & Confirmed & 3.52 & 0.95 \\
\hline & Direct access of patients to their medical records & 0.8 & Confirmed & 3.61 & 0.91 \\
\hline & $\begin{array}{l}\text { Adequate access of the physician to the patient's medical } \\
\text { records }\end{array}$ & 0.8 & Confirmed & 3.47 & 1.009 \\
\hline & Quality of services & 0.8 & Confirmed & 3.47 & 0.96 \\
\hline & Continuous provision of care & 1 & Confirmed & 3.54 & 0.94 \\
\hline & Promotion of preventive care & -0.8 & Rejected & & \\
\hline \multirow{9}{*}{$\begin{array}{l}\text { Structural } \\
\text { factors }\end{array}$} & Accurate information security and privacy & 1 & Confirmed & 3.70 & 0.96 \\
\hline & $\begin{array}{l}\text { The role of universities and determining the scope of } \\
\text { authority }\end{array}$ & 1 & Confirmed & 3.66 & 0.89 \\
\hline & Distribution of equipment between different centers & 1 & Confirmed & 3.94 & 0.84 \\
\hline & No access of patients to their medical records & -1 & Rejected & \multicolumn{2}{|c|}{-} \\
\hline & $\begin{array}{l}\text { Insufficient access of the physician to the patient's } \\
\text { medical records }\end{array}$ & -1 & Rejected & \multicolumn{2}{|c|}{ - } \\
\hline & International restrictions on information sharing & 1 & Confirmed & 4.02 & 0.85 \\
\hline & Lack of medical guidelines in telemedicine & 0.8 & Confirmed & 3.35 & 1.09 \\
\hline & $\begin{array}{c}\text { Barriers to technology adoption, such as complex and } \\
\text { time-consuming administrative processes }\end{array}$ & -1 & Rejected & \multicolumn{2}{|c|}{-} \\
\hline & Continuity of supply and credit & 0.8 & Confirmed & 3.58 & 0.95 \\
\hline
\end{tabular}




\begin{tabular}{|c|c|c|c|c|c|}
\hline \multirow{9}{*}{$\begin{array}{l}\text { Technological } \\
\text { factors }\end{array}$} & Computer system usability & 0.8 & Confirmed & 4.22 & 0.87 \\
\hline & $\begin{array}{l}\text { Reliability of technology (responsibility and training) and } \\
\text { computer system }\end{array}$ & 0.8 & Confirmed & 3.98 & 1.03 \\
\hline & User-friendliness of telemedicine & 0.8 & Confirmed & 3.89 & 0.91 \\
\hline & $\begin{array}{l}\text { Connection between telemedicine network and the } \\
\text { government system to confirm the identity of patients }\end{array}$ & 0.8 & Confirmed & 3.82 & 1.03 \\
\hline & Risk of equipment failure & 0.8 & Confirmed & 3.88 & 1.01 \\
\hline & Infrastructure & 0.8 & Confirmed & 3.47 & 1.14 \\
\hline & Integration of heterogeneous systems & 0.8 & Confirmed & 3.47 & 1.06 \\
\hline & Development of intelligent systems & 1 & Confirmed & 3.24 & 1.11 \\
\hline & Messaging standards & 1 & Confirmed & 3.76 & 1.01 \\
\hline \multirow[t]{8}{*}{$\begin{array}{l}\text { Economic } \\
\text { factors }\end{array}$} & $\begin{array}{l}\text { Less costly methods in financial, social and } \\
\text { environmental interactions }\end{array}$ & 1 & Confirmed & 3.49 & 1.10 \\
\hline & Reduction of hospitalization costs & 1 & Confirmed & 3.47 & 1.08 \\
\hline & Medical equipment costs & 1 & Confirmed & 3.44 & 1.07 \\
\hline & Specialist payroll & 1 & Confirmed & 3.28 & 0.94 \\
\hline & Threatening insurance companies to pay premiums & 0.8 & Confirmed & 3.52 & 0.92 \\
\hline & Market forces and competitors & 1 & Confirmed & 3.42 & 1.01 \\
\hline & Budget constraints & 0.8 & Confirmed & 3.42 & 0.99 \\
\hline & Private insurance coverage & 0.8 & Confirmed & 3.51 & 0.98 \\
\hline \multirow[t]{5}{*}{ Legal factors } & $\begin{array}{l}\text { Determination of a framework and issuance of third-party } \\
\text { certificates for patients to access their medical records }\end{array}$ & 0.8 & Confirmed & 3.42 & 0.95 \\
\hline & Framework of instructions and validation & 0.8 & Confirmed & 3.57 & 0.88 \\
\hline & $\begin{array}{l}\text { Reliability and variety of clinical guidelines and } \\
\text { regulations }\end{array}$ & 1 & Confirmed & 3.42 & 0.97 \\
\hline & $\begin{array}{l}\text { The role of the Ministry of Health and Medical Education } \\
\text { in e-health }\end{array}$ & 1 & Confirmed & 3.48 & 0.96 \\
\hline & Focus on public health services & 1 & Confirmed & 3.47 & 0.92 \\
\hline Policymaking & Insurance supervision & 1 & Confirmed & 3.22 & 0.92 \\
\hline
\end{tabular}




\begin{tabular}{|c|c|c|c|c|c|}
\hline \multirow[t]{6}{*}{ factors } & $\begin{array}{l}\text { Necessary framework for formulating rules and } \\
\text { guidelines }\end{array}$ & 1 & Confirmed & 3.51 & 0.98 \\
\hline & Concerns about the system's user-friendliness & -1 & Rejected & \multicolumn{2}{|c|}{-} \\
\hline & Insurance responsibility protocols & 1 & Confirmed & 3.53 & 0.93 \\
\hline & Development of care delivery guidelines & 1 & Confirmed & 3.56 & 1.007 \\
\hline & $\begin{array}{l}\text { Necessary rules for encrypting patients' security } \\
\text { information }\end{array}$ & 1 & Confirmed & 3.22 & 0.95 \\
\hline & Documents contained in clinical cases for judicial barriers & 1 & Confirmed & 3.47 & 1.03 \\
\hline \multirow[t]{6}{*}{$\begin{array}{l}\text { Cultural } \\
\text { factors }\end{array}$} & $\begin{array}{c}\text { Technology-based trust and cooperation between partners } \\
\text { without knowing each other }\end{array}$ & 0.8 & Confirmed & 3.11 & 0.96 \\
\hline & Transparency and security of all exchanges in general & 0.8 & Confirmed & 3.05 & 1.03 \\
\hline & Necessary tools for interaction and implementation & 0.8 & Confirmed & 3.26 & 1.10 \\
\hline & $\begin{array}{c}\text { The degree of cooperation and high scale in the health } \\
\text { system }\end{array}$ & 0.8 & Confirmed & 3.52 & 1.03 \\
\hline & $\begin{array}{l}\text { Interaction between experts at the national and } \\
\text { international levels }\end{array}$ & 0.8 & Confirmed & 3.14 & 1.03 \\
\hline & $\begin{array}{l}\text { Improvement of communication skills and proper } \\
\text { interaction }\end{array}$ & -1 & Rejected & & \\
\hline
\end{tabular}

\section{Quantitative study}

Of the 384 participants of this study, 226 participants $(58.9 \%)$ were female and the rest of them were male. Most of the participants aged $41-45$ years $(27.6 \%)$, has a master's degree $(50 \%)$, and had 10-15 years of work experience (41.9\%). Among the factors related to service providers, the highest mean belonged to "increasing the individual and professional skills of service providers" (3.31 \pm 0.88$)$ and the lowest mean was related to "unequal geographical distribution and lack of specialists in remote areas" (3.20 0.98$)$. Among the factors related to service recipient, the highest mean was related to "patient satisfaction" $(3.63 \pm 0.93)$ and the lowest mean belonged to "adequate access of the physician to the patient's medical records" (3.47 \pm 1.001$)$. Among the structural factors, the highest mean was related to "international restrictions on information sharing $(4.02 \pm 0.85)$ and the lowest mean belonged to "lack of medical guidelines in telemedicine" (3.35 \pm 1.09$)$. Among the technological factors, the highest and the lowest mean scores were related to "reliability of technology (responsibility and training) and computer system" (4.22 \pm 0.87$)$ and "development of intelligent systems" (3.24 \pm 1.11$)$, respectively. Among economic factors, the highest mean was related to "private insurance coverage" $(3.51 \pm 0.98)$ and the lowest mean belonged to "specialist payroll" (3.28 \pm 0.94$)$. Among legal 
factors, the highest mean was related to "framework of instructions and validation" (3.57 \pm 0.88$)$ and the lowest mean belonged to "reliability and variety of clinical guidelines and regulations" (3.42 \pm 0.97$)$. Among policymaking factors, the highest and the lowest mean scores were related to "development of care delivery guidelines" $(3.56 \pm 1.007)$ and "confidence and rules required to encrypt patient security information" (3.22 \pm 0.95$), \quad$ respectively.
Among cultural factors, the highest mean belonged to "degree of cooperation and high scale in the health system" $(3.52 \pm 1.03)$ and the lowest mean was related to "transparency and security of all exchanges in general" (3.05 \pm 1.03$)$ (Table 2).

In general, cultural factors $(3.95 \pm 0.77)$ and policymaking factors (3.22 \pm 0.84$)$, respectively, had the highest and the lowest effects on the establishment of teledermatology in Iran.

Table 2: Frequency distribution of the factors affecting the establishment of teledermatology in Iran

\begin{tabular}{|c|c|c|c|c|}
\hline Variable & Mean & Standard deviation & Minimum & Maximum \\
\hline Service provider & 3.56 & 0.74 & 1.5 & 5 \\
\hline Service recipient & 3.44 & 0.83 & 1.36 & 5 \\
\hline Technological factors & 3.63 & 0.74 & 1.89 & 5 \\
\hline Economic factors & 3.25 & 0.83 & 1 & 5 \\
\hline Structural factors & 3.41 & 0.78 & 1 & 5 \\
\hline Policymaking factors & 3.22 & 0.84 & 1.6 & 5 \\
\hline Cultural factors & 3.95 & 0.77 & 1 & 5 \\
\hline Legal factors & 3.48 & 0.88 & & 5 \\
\hline
\end{tabular}

\section{Discussion}

The increasing burden of skin diseases in developing and developed countries has caused the demand for dermatology services to be more than the current supply. Teledermatology seems to be able to settle some of the health care differences. Moreover, many patients in developing countries do not have access to a dermatologist (21). These items emphasize the need for the establishment of teledermatology.

The study results showed that technological factors are among the most important variables affecting the establishment of teledermatology in Iran. Manarao (2018) (22), Fogel (2016) (23), Al-Jalani (2013) (24), Elahi (2013) (25), Martin (2012) (26), Oikonomomo (2009) (27), and Maya (2006) (28) also reported that technology is one of the factors influencing the establishment of 
teledermatology. These findings indicate that the establishment of teledermatology requires sufficient infrastructure such as high-speed Internet and remote medical hardware. In addition, hospitals should provide the necessary equipment for teledermatology.

Structural factors are another variable affecting the establishment of teledermatology in Iran. The studies conducted by Young (2018) (29), Manarao (2018) (22), Rajeda (2018) (15), Fogel (2016) (23), Nevilo (2016) (30), Cande (2013) (31), Al-Jalani (2013) (24), Martin (2012) (26), and Van Derberg (2012) (32) demonstrated that structural factors are among the factors affecting the establishment of teledermatology.

The factors related to service providers are also among other variables affecting the establishment of teledermatology in Iran. Young (2018) (29), Chang (2018) (33), Tol (2017) (34), Agnisarman (2017) (35), Van Derberg (2012) (32), and Oikonomu (2009) (27) reported that the factors related to service providers affect the establishment of teledermatology. Holding training workshops and on-the-job courses for the medical staff can be effective in increasing the awareness of service providers and the familiarity with teledermatology equipment.

Another variable affecting the establishment of teledermatology in Iran are the factors related to service recipients. The studies conducted by Rajda (15), Chang (33), Manarao (2018) (22), Tol (2017) (34), Campaigna (2017) (36), Livit (2016) (35), and Neuilu (2016) (30) showed that the factors related to service recipients also affect the establishment of teledermatology. The results of this study indicated that the most important factor in this regard was patient satisfaction. Patient satisfaction is one of the major goals of Iran's Ministry of Health and Medical Education and Iranian universities of medical sciences (37). The provision of highquality services to patients not only motivates the patients to continue their treatment but also brings individual and social benefits (38).

Economic factors are among the variables affecting the establishment of teledermatology in Iran. Raja (15), Campagna (36), Tol (34), Van Derberg (32), and Oikonomou (27) reported that economic factors are among the variables affecting the establishment of teledermatology. When implementing new technology in organizations, it should be taken into account that the initial investment and financial resources must be combined with the human resources and experienced and technical staff because providing equipment without proper and efficient users will not be effective (39).

Another group of variables affecting the establishment of teledermatology in Iran is cultural factors. Kimberly et al. (2015) emphasized the significance of organizational culture as a prerequisite for the successful establishment of telemedicine (40). Salehahmadi and Hajaliasghari stated that cultural, linguistic, and literacy differences are a major barrier to the effective establishment of telemedicine in Iran. They also argued that linguistic and cultural differences between patients and incompatible cultural services and subsystems are the main challenges for the transfer of knowledge from a cultural environment to another (3). Mortazavi et al. stated that one of the problems is the poor culture patients in using such systems. Accordingly, most patients are reluctant to be examined remotely and prefer to have a face-to-face visit with the physician (41). A study conducted by Dargahi et al. showed that most participants emphasized the need for the existence of a clear executive 
culture for the successful establishment of telemedicine (42). In this regard, public and private educational systems are recommended to try to improve the literacy level, bridge cultural gaps, and employ modern technologies such as distance learning to pave the way for the replacement of traditional methods of service with telemedicine (43).

Some of the limitations of this study were as follows. It was difficult to convince the members of the study population to participate in the study. This problem was resolved through academic correspondence, continuous follow-up, and justification of the study's significance. Since a few studies have been conducted about the establishment of teledermatology in Iran, the study findings were compared with the results of similar studies conducted in other countries. Considering the hectic work schedule of interviews, the time and place of interviews were set in consultation with themselves so that they could attend the interview when they had fewer mental concerns. In the quantitative section, the cross-sectional nature of the study was one of the main limitations of this study. Also, the geographical distribution of the study population and delay in the completion of questionnaires made the authors use several remainders.

In order to conduct future studies, it is recommended to design a model of Establishment of Teledermatology. Also, feasibility study and pilot study is done to implement Teledermatology in Iran.

\section{Conclusion}

Effective Factors on the establishment of teledermatology were extracted in the study. This can help the policymakers and managers interested in the establishment of teledermatology to identify top-priority factors in this regard to save time and money in teledermatology implemention.Therefore, it is recommended that These infrastructural factors to use in different parts of the establishment.

\section{Acknowledgments:}

The authors would like to thank all who helped us in this study.

\section{References}

1. Coates SJ, Kvedar J, Granstein RD. Teledermatology: from historical perspective to emerging techniques of the modern era: part I: history, rationale, and current practice. Journal of the American Academy of Dermatology. 2015;72(4):563-74.

\section{(DOI:10.1016/j.jaad.2014.07.061)}

2. Chellaiyan VG, Nirupama A, Taneja N. Telemedicine in India: Where do we stand? Journal of Family Medicine and Primary Care. 2019;8(6):1872.

\section{(DOI:10.4103/jfmpc.jfmpc 264 19)}

3. Salehahmadi Z, Hajialiasghari F. Telemedicine in Iran: chances and challenges. World journal of plastic surgery. 2013;2(1):18.

4. Ayatollahi H, Khoei A, Mohammadian N, Sadeghian MH, Azari JB, Ghaemi MR, et al. Telemedicine in diagnostic pleural cytology: a feasibility study between universities in Iran and the USA. Journal of telemedicine and telecare. 2007;13(7):363-8.

\section{(DOI:10.1258/135763307782215343)}

5. Panse N. Telemedicine and plastic surgery in India. World journal of plastic surgery. 2014;3(1):70-1.

6. Safdari R, Masouri N, Ghazi Saeedi M, Sharifian R, Soltani A, Shahmoradi L. Wireless and mobile systems in telemedicine. ISMJ. 2012;15(4):327-38.

7. Aoki N, Dunn K, Johnson-Throop KA, Turley JP. Outcomes and methods in telemedicine 
evaluation. Telemedicine Journal and e-Health. 2003;9(4):393-401.

\section{(DOI:10.1089/153056203772744734)}

8. Keshvari H, Haddadpoor A, Taheri B, Nasri M, Aghdak P. Survey determinant factors of telemedicine strategic planning from the managers and experts perspective in the health department, isfahan university of medical sciences. Acta Informatica Medica. 2014;22(5):320. (DOI:10.5455/aim.2014.22.320-324)

9. Ajami S, Arzani-Birgani A. The use of telemedicine to treat prisoners. J Inform Tech Soft Engg. 2013;7:e002. (DOI:10.4172/2165-7866.S7e002)

10. Darvish A, Far M. A review on implementation of electronic health in Iran literature. MOJ Womens Health. 2017;5(5):00136.

\section{(DOI:10.15406/mojwh.2017.05.00136)}

11. Zakaria A, Maurer T, Su G, Amerson E. Impact of teledermatology on the accessibility and efficiency of dermatology care in an urban safetynet hospital: A pre-post analysis. Journal of the American Academy of Dermatology. 2019;81(6):1446-52.

\section{(DOI:10.1016/j.jaad.2019.08.016)}

12. Azfar RS, Weinberg JL, Cavric G, LeeKeltner IA, Bilker WB, Gelfand JM, et al. HIVpositive patients in Botswana state that mobile teledermatology is an acceptable method for receiving dermatology care. Journal of telemedicine and telecare. 2011;17(6):338-40. (DOI:10.1258/jtt.2011.110115)

13. Reichert A, Jacobs R. The impact of waiting time on patient outcomes: Evidence from early intervention in psychosis services in E ngland. Health economics. 2018;27(11):1772-87. (DOI:10.1002/hec.3800)

14. Yim KM, Florek AG, Oh DH, McKoy K, Armstrong AW. Teledermatology in the United States: an update in a dynamic era. Telemedicine and e-Health. 2018;24(9):691-7. (DOI:10.1089/tmj.2017.0253)
15. Rajda J, Seraly MP, Fernandes J, Niejadlik K, Wei H, Fox K, et al. Impact of direct to consumer store-and-forward teledermatology on access to care, satisfaction, utilization, and costs in a commercial health plan population. Telemedicine and e-Health. 2018;24(2):166-9. (DOI:10.1089/tmj.2017.0078)

16. Finnane A, Dallest K, Janda M, Soyer HP. Teledermatology for the diagnosis and management of skin cancer: a systematic review. JAMA dermatology. 2017;153(3):319-27. (DOI:10.1001/jamadermatol.2016.4361)

17. Damari B, Hajebi A, Bolhari J, Heidari A. Developing a Training Course for Spiritual Counselors in Health Care: Evidence from Iran. Indian J Palliat Care. 2018;24(2):145-149. (DOI:10.4103/IJPC.IJPC 207 17)

18. Heidari A, Arab M, Etemad K, Damari B. challenges of implementation of the national phenylketonuria screening program in Iran: a qualitative study. Electronic physician 2016;8(10): 3048. (DOI:10.19082/3048)

19. Heidari A, Arab M, Etemad K, Damari B, lotfi M. National phenylketonuria screening program in Iran; why and how. SJSPH 2018; 16(2):148163.

20. Etemad K, Heidari A, Panahi MH, Lotfi M, Fallah F, Sadeghi S. Challenges of Access to Data of Ministry of Health from the Perspective of Policy-makers, Producers, and Consumers of Data: A Qualitative Study. Iranian Journal of Epidemiology 2017; 13 (3): 174-182.

21. Coates SJ, Kvedar J, Granstein RD. Teledermatology: from historical perspective to emerging techniques of the modern era: part II: emerging technologies in teledermatology, limitations and future directions. Journal of the American Academy of Dermatology. 2015;72(4):577-86.

\section{(DOI:10.1016/j.jaad.2014.08.014)}

22. Mannaro K, Baralla G, Pinna A, Ibba S. A blockchain approach applied to a teledermatology platform in the Sardinian region (Italy). 
Information.

2018;9(2):44.

(DOI: 10.3390/info9020044)

23. Fogel AL, Teng J, Sarin KY. Direct-toconsumer teledermatology services for pediatric patients: Room for improvement. Journal of the American Academy of Dermatology. 2016;75(5):887-8.

(DOI:10.1016/j.jaad.2016.08.002)

24. Alajlani M, Clarke M. Effect of culture on acceptance of telemedicine in Middle Eastern countries: case study of Jordan and Syria. Telemedicine and e-Health. 2013;19(4):305-11. (DOI:10.1089/tmj.2012.0106)

25. Ilahi L, Ghannouchi SA. Improving telemedicine processes via BPM. Procedia Technology. 2013;9:1209-16. (DOI:10.1016/j.protcy.2013.12.135)

26. Martin AB, Probst JC, Shah K, Chen Z, Garr D. Differences in readiness between rural hospitals and primary care providers for telemedicine adoption and implementation: findings from a statewide telemedicine survey. The Journal of Rural Health. 2012;28(1):8-15. (DOI:10.1111/j.1748-0361.2011.00369.x)

27. Oikonomou S, Gwynedd Y, Trust N, editors. Teledermatology: Digital revolution in the management of skin disease. Proceedings of the 2nd WSEAS international conference on Biomedical electronics and biomedical informatics; 2009: World Scientific and Engineering Academy and Society Stevens Point, WI.

28. Maia RS, von Wangenheim A, Nobre LF, editors. A statewide telemedicine network for public health in brazil. 19th IEEE Symposium on Computer-Based Medical Systems (CBMS'06); 2006: IEEE. (DOI:10.1109/CBMS.2006.29)

29. Yeung H, Sargen MR, Luk KM, Berry EG, Gurnee EA, Heuring E, et al. Teledermatology and teledermatopathology as educational tools for international dermatology: a virtual grand rounds pilot curriculum. International journal of dermatology.

2018;57(11):1358-62. (DOI:10.1111/ijd.14014)

30. Novillo-Ortiz D, D'Agostino M, BecerraPosada F. El rol de la OPS/OMS en el desarrollo de capacidad en eSalud en las Américas: análisis del período 2011-2015. Revista Panamericana de Salud Pública. 2016;40:85-9.

31. O'Reilly M, Nason G, Liddy S, Fitzgerald C, Kelly M, Shields C. DOCSS: doctors on-call smartphone study. Irish Journal of Medical Science (1971-). 2014;183(4):573-7. (DOI:10.1007/s11845-013-1053-4)

32. van den Berg N, Schumann M, Kraft K, Hoffmann W. Telemedicine and telecare for older patients-A systematic review. Maturitas. 2012;73(2):94-114.

\section{(DOI:10.1016/j.maturitas.2012.06.010)}

33. Cheung C-mM, Muttardi K, Chinthapalli S, Ismail F. Pilot Teledermatology Service for Assessing Solitary Skin Lesions in a Tertiary London Dermatology Center. The Journal for Healthcare Quality (JHQ). 2019;41(1):e1-e6. (DOI:10.1097/JHQ.0000000000000142)

34. Tull R, Wanat KA, editors. Teledermatology in the inpatient setting. Seminars in cutaneous medicine and surgery; 2017. (DOI:10.12788/j.sder.2017.004)

35. Leavitt ER, Kessler S, Pun S, Gill T, Escobedo LA, Cockburn M, et al. Teledermatology as a tool to improve access to care for medically underserved populations: A retrospective descriptive study. Journal of the American Academy of Dermatology. 2016;75(6):1259-61.

\section{(DOI:10.1016/j.jaad.2016.07.043)}

36. Campagna M, Naka F, Lu J. Teledermatology: An updated overview of clinical applications and reimbursement policies. International journal of women's dermatology. 2017;3(3):176-9. (DOI:10.1016/j.ijwd.2017.04.002)

37. Keshtkaran A, Taft V, Keshtkaran V, Heidari A, Shahmohammadi J, Dehbozorgi M, et al. 
Client Tribute Plan and Patient Satisfaction in Shiraz Hospitals. Journal of Payavard Salamat. 2017;11(1):115-23.

38. Keshtkaran A, Heidari AR, Keshtkaran V, Taft V, Almasi A. Satisfaction of outpatients referring to teaching hospitals clinics in Shiraz, 2009. Payesh (Health Monitor). 2012;11(4):45965.

39. Nobakht $S$, Bagheri $S$, Mehraeen E, Shamsabadi AR. The Feasibility of Telemedicine Technology Implementation in the Selected Hospitals of Iran. Journal of Payavard Salamat. 2018;12(1):25-33.

40. Merchant K, Ward M, Mueller K. Hospital Views of Factors Affecting Telemedicine Use. Rural policy brief. 2015(2015 5):1-4.

41. Montazeri M, Bahaadinbeigy K, Tofighi S. Design And Implementation A Web Base
Teledermatology System To Reduce Provincial Travelling In Kerman Medical University. 2015.

42. Dargahi H, Razavi M. The role of organizational culture in impelenting telemedicine technology in healthcare centers Tehran university of Medical Scinces 1382-1383. Journal of Medical Faculty. 2011;2:99-107.

43. Sadoughi F, Moulaei K, Ahmadi Farsani M, Hadian M. Effciency and effectiveness of telemedicine in the management and monitoring of heart disease: Systematized review. Journal of Modern Medical Information Science. 2018;4(2):51-9.

\section{How to cite:}

Kazemi S.B, Jafari M, Hosseini S.M, Maher A, Bahadori M.K. Factors Affecting the Establishment of Teledermatology in Iran; A Mixed-Method Study. Jorjani Biomedicine Journal. 2020; 8(1): 11-23. 